\title{
Disaster risk assessment for urban areas: A GIS flood risk analysis for Luján City (Argentina).
}

\author{
Ignacio Agustin Gatti ${ }^{\text {a, }}$ *, Takashi Oguchi ${ }^{\text {a, b }}$ \\ ${ }^{a}$ Department of Natural Environmental Studies, Graduate School of Frontier Sciences, The University of Tokyo, Japan. \\ gatti@csis.u-tokyo.ac.jp,oguchi@csis.u-tokyo.ac.jp \\ ${ }^{b}$ Center for Spatial Information Science, The University of Tokyo, Japan \\ * Corresponding author:
}

Keywords: flood risk; vulnerability, exposure, hazard, GIS.

\begin{abstract}
:
Floods frequently cause disasters worldwide. In Argentina, almost half of disasters are related to floods (Celis \& Herzer, 2003). During the period 1944 to 2005, 41 major floods occurred in urban areas in the country (Argentina Red Cross, 2010 ) with more than 13 million people affected. Luján $\left(34^{\circ} 33^{\prime} \mathrm{S}, 59^{\circ} 07^{\prime} \mathrm{W}\right)$ is a city of about 110,000 people, situated 21 $\mathrm{m}$ above the mean sea level in a relatively plain area. It suffered from 21 floods between 1967 and 2018 with a result of about 14,600 evacuees and 3 dead people. The main cause of the floods is the overflow of the Luján River, which has an average flow of $5.37 \mathrm{~m}^{3} / \mathrm{s}$ (INA, 2007).

The National Disaster Risk Assessment guidelines (UNDP, 2010; UNSIDR, 2018) outline the use of qualitative or quantitative approaches to determinate the acceptable level of risk. Risk has been associated with a potential loss with different levels of certainty (Crichton, 1999; WMO, 2013), and it could be defined as a combination of hazard, exposure and vulnerability (Akhtar et al, 2018; Behanzin, 2015; Armeneakis et al., 2017; UNISDR, 2017) (Figure 1). If one of those elements is missing, risk is not defined. The hazard is related to the potential danger that the natural phenomenon has, which is inherent to the event itself, and it would be inundation scenarios in this study. Vulnerability has been defined by Cardona et al. (2012) as a propensity or predisposition to be adversely affected. That definition includes the characteristics of a person or a group, and their situation that influences their capacity to anticipate, cope with, resist, and recover from the adverse effects of physical events (Natenzon et al., 2005; González, 2009). The perspectives selected in the present work focus on working with social vulnerability which is linked to socio-economical population conditions and the possibility of these being affected. Spatial distribution of exposure (elements at risk) in proximity to a hazard is a significant factor of disaster risk (UNISDR, 2017). Some researchers (González et al., 1998; Villagrán De León, 2001; Moel et al., 2009) defined "exposure" as what can be affected by a flood such as buildings, land use, and population, the latter of which is a significant factor of disaster risk (UNISDR, 2017). Flood risk maps play an important role in decisionmaking, planning and implementing flood management options (WMO, 2013).
\end{abstract}

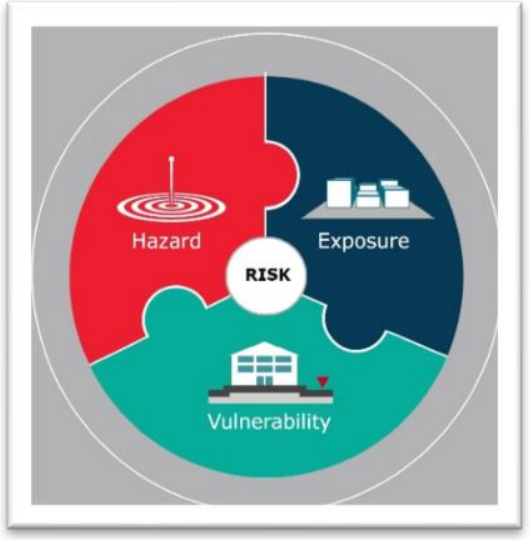

Figure 1 - Understanding of Disaster Risk. Modified after UNSIDR (2017).

Geographical Information Systems (GIS) enable us to perform a spatial analysis of the elements of risk (hazard, vulnerability, and exposure) for Luján City. By creating categories from the selection of some indicators, it is possible to define which area is more likely to be impacted by a flood, which population and which infrastructure are more exposed, and who is more vulnerable. A final flood risk index is created with five categories based on risk values from 0 (lowest) to 1 (highest) (Figure 2). 


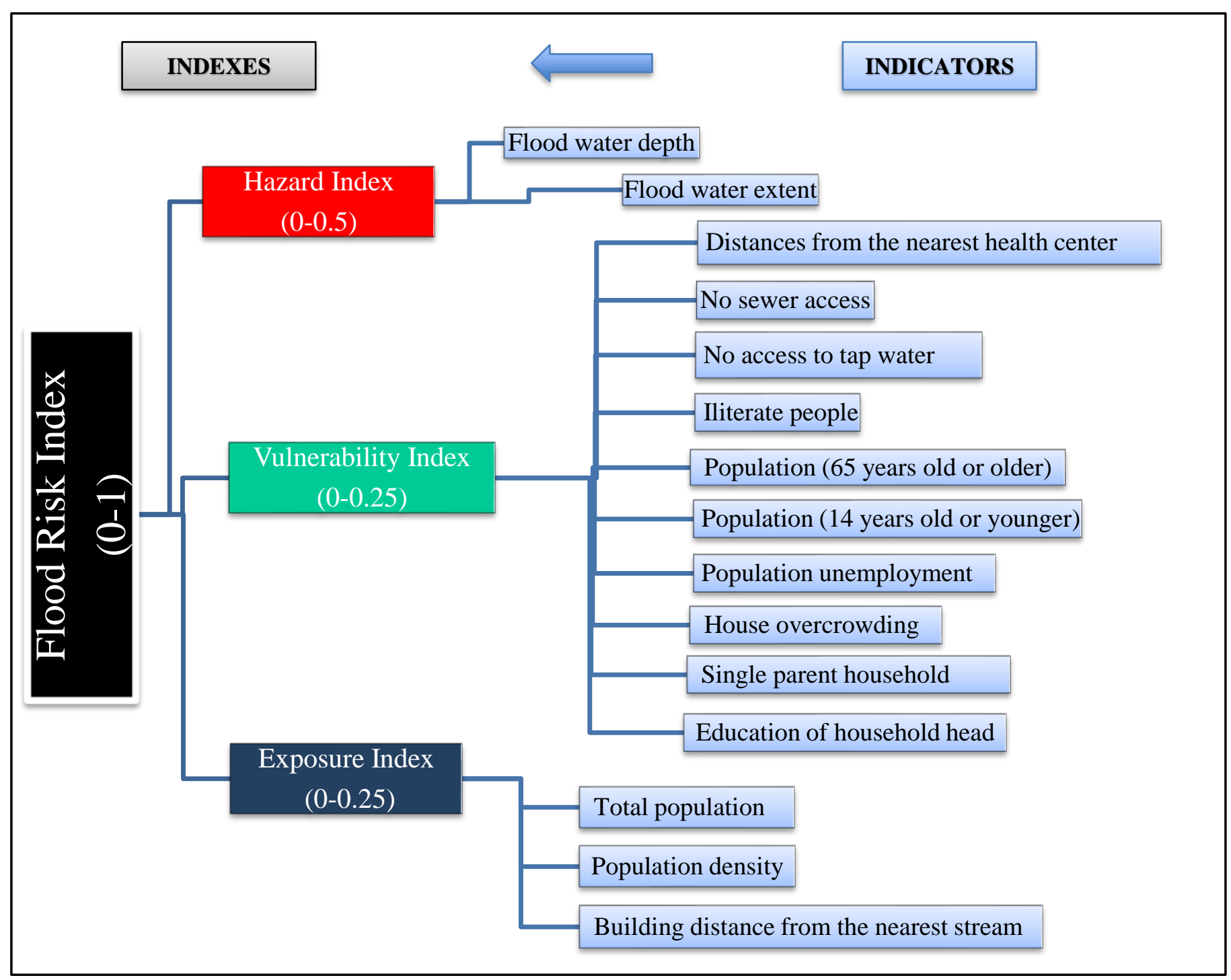

Figure 2 - Selected risk indexes and indicators.

Hazard analysis is made by using a 5-m Digital Elevation Model (DEM), rainfall data, land use information, drainage system (sewers and streams) and historical flood maps. Sources of vulnerability and exposure indicators are data from the last National Argentinian Census in the year 2010.

Although it is impossible to totally eliminate the flood risk, it is possible to mitigate some consequences. Findings from this study illustrate that some areas of higher flood risk coincide with areas of high flood hazard, more exposed, and more vulnerable. This methodology helps to develop disaster risk management strategies for settlements frequently flooded. 